\title{
Effects of Sodium Chlorite on Browning and Microbial Growth of Fresh-Cut 'Green Oak' Lettuce
}

\author{
Daneeya Hengphum ${ }^{1,2}$, Apiradee Uthairatanakij ${ }^{1,2}$, Panida Boonyaritthongchai ${ }^{1,2}$, \\ Nutthachai Pongprasert ${ }^{1,2}$, Pongphen Jitareerat ${ }^{1,2, *}$ \\ ${ }^{1}$ Division of Postharvest Technology, School of Bioresources and Technology, King Mongkut's University of Technology Thonburi, Bangkok, \\ Thailand \\ ${ }^{2}$ Postharvest Technology Innovation Center, Commission of Higher Education, Bangkok, Thailand
}

Email address:

pongphen.jit@kmutt.ac.th (P. Jitareerat)

\section{To cite this article:}

Daneeya Hengphum, Apiradee Uthairatanakij, Panida Boonyaritthongchai, Nutthachai Pongprasert, Pongphen Jitareerat. Effects of Sodium Chlorite on Browning and Microbial Growth of Fresh-Cut 'Green Oak' Lettuce. Journal of Food and Nutrition Sciences. Special Issue: Food Processing and Food Quality. Vol. 3, No. 1-2, 2015, pp. 171-176. doi: 10.11648/j.jfns.s.2015030102.43

\begin{abstract}
The main problem of fresh-cut lettuce is browning at the cut surface and microbial contamination, which results in short shelf life. The effect of sodium chlorite (SC) on browning reduction and microbial growth on fresh-cut 'Green oak' lettuce salad was investigated. Green oak lettuce was washed with tap water before cutting into $3 \mathrm{~cm}$ of length. The samples were immediately immersed the cold solutions $\left(4^{\circ} \mathrm{C}\right)$ of 50 and $100 \mathrm{ppm} \mathrm{SC}$ for $1 \mathrm{~min}$. The cold filtered water treatment was used as the control. The excess solution was removed by manual spindle. The treated samples were packed in polypropylene tray, top heated seal with polypropylene film, and then kept at $4{ }^{\circ} \mathrm{C}$ for 8 days. The results showed $100 \mathrm{ppm} \mathrm{SC}$ was the best concentration to reduce browning, the growth of $E$. coli and coliforms, and delay the increase of weight loss in fresh-cut green oak, whereas it did not have any effects on the growth of total aerobe bacteria, yeasts and molds, and firmness of fresh-cut green oak. This result implies that SC solution may be alternative substance to against browning and the growth of $E$. coli and coliforms in fresh-cut produce.
\end{abstract}

Keywords: Browning, Fresh-Cut, Sodium Chlorite, Microbial Growth, Vegetables

\section{Introduction}

Nowadays, the consumption of fresh-cut vegetables, particularly lettuce salads, tends to increase in many countries in the world, especially in the city. Because, living hastily of people and work against time cause required ready to eat vegetables, and the consumers also concern about being of good health. In fresh-cut process, washing before cutting was a first steps for remove dust, pesticides and reduce microbial populations. Cutting operation was important step, the cause of tissue damage which leading to easily contamination by microbial and rapid browning of cut surface resulting to rapid deterioration and short shelf life (Degl' Innocenti et al., 2007). Therefore, washing after cutting again it helps remove cellular juice at the cut surface which is the source of foods for microbial growth. Moreover, when cellular juice exposures with oxygen it will occur browning reaction (Zagory, 1999). This reaction is caused by oxidation of phenolic compounds, oxidised to quinones and catalysed by polyphenol oxidase (PPO) (Altunkaya \& Gökmen, 2009). Controls of enzymatic browning activities and microbial growth are important to maintain quality and prolong shelf life of fresh-cut produce (Luo et al., 2011). Several agents have been used to inhibit browning and reduce microbial of fresh-cut produce. There are many reports investigated the efficiency of anti-browning agents in fresh-cut salads such as calcium lactate, ascorbic acid, chlorine dioxide, cysteine, phytoncide, citric acid, calcium chloride, sodium metabisulphite (sulphite), L-cysteine and acetic acid (Martin-Diana et al., 2005; Gómez-López, 2008; Chen et al., 2010; Kim et al., 2014; Manolopoulou \& Varzakas, 2013; Ibrahim et al., 2004). Anti-microbial agent generally used in fresh-cut salads is chlorine group included chlorine, acidic electrolyzed water and chlorine dioxide (Keskinen et al., 2009). However, using the agents which have dual mode of action as the anti-microbial and anti- 
browning may be good to solve the major problem in freshcut produce.

Sodium chlorite (SC) is a strong oxidizing agent and effective disinfection. The formula is $\mathrm{NaClO}_{2}$. It is a sanitizing agent which has been accepted by the FDA for use in food. It has been reported that effect of SC on inhibiting browning and microbial growth in fresh-cut fruit and vegetables. For example, Allende et al. (2008) found that yeasts and moulds populations were decreased after washing with Sanova (commercial sanitizer agents of acidified sodium chlorite) on fresh-cut escarole and lettuce. Allende et al. (2009) reported that SC reduced aerobic mesophilic bacteria and E. coli $\mathrm{O} 157: \mathrm{H} 7$ populations whereas yeast and mould populations were not reduced on fresh-cut cilantro. The effect of SC in preventing browning has been investigated in several fresh-cut produce; zucchinis, cucumber, carrot, green bell pepper, radish (Sun et al., 2012) and apple slices (Lu et al., 2007)

Although, it has been report suggested that SC for inhibit browning and reduce microbial in many fruits and vegetables. There was no studied on the effect of SC on fresh-cut Green oak lettuce. The aim of this work was to study the efficacy of sodium chlorite at different concentrations to against browning and microbial growth on fresh-cut Green oak lettuce.

\section{Material and Methods}

\subsection{Plant Materials and Treatments}

Green oak lettuces purchased from the farm of Adam Enterprises Ltd. were washed with tap water to remove soil, dust and plant debris before cutting into $3 \mathrm{~cm}$ of length. The cut samples were immediately immersed the cold solution (4 ${ }^{\circ} \mathrm{C}$ ) of 50 and $100 \mathrm{ppm}$ sodium chlorite for $1 \mathrm{~min}$. The cut samples treated with cold filtered water was used as the control. The excess solution was removed with a manual spindle. Afterwards, 60 grams of the treated samples were packed in polyethylene tray $(14 \times 19 \times 5 \mathrm{~cm})$ and heat sealed with polyethylene film. All samples were then stored at $4{ }^{\circ} \mathrm{C}$ for 8 days. Each treatment included with three replicates (trays).

\subsection{Quality Assessment of Fresh-Cut Green Oak Lettuce}

Ten persons of untrained testing panel evaluated browning score. The browning score on the cut surface of lettuce was assessed as the following, where $0=$ non-browning, $1=$ slightly brown on the cut surface, 2 = moderate brown on the cut surface, 3 = severe brown on the cut surface and extend to mid rib, and $4=$ extremely severe brown on the cut surface and extend to mid rib. The weight loss of each fresh-cut green oak lettuce was determined with a balance (model Pioneer PA4102, Ohaus Corporaion, Parsippany, NJ, USA) one day interval until the end of the storage times. The percentage of weight loss was calculated by dividing the number of gram had lost by initial sample weight, subtract final sample weight at the indicated period and then multiplying that number by 100 . The shear force evaluation was measured using texture analyzer (model TA-XT2, Texture Technologies Corporation, Scandale, NY, USA) equipped with knife blade with $45^{\circ}$ chisel. The result was expressed as Newton.

\subsection{Microbial Analysis in Fresh-Cut Green Oak Lettuce}

Ten grams of fresh-cut samples were mixed with $90 \mathrm{ml}$ of sterilized peptone water solution and homogenized in a stomacher (model Masticator Nr 2759/400, IUL instruments, Barcelona, Spain) for $1 \mathrm{~min}$. The growth media and incubation conditions as follow: Plate count agar (PCA) was used for total aerobe bacteria. Incubate of the plates at $37{ }^{\circ} \mathrm{C}$ for $72 \mathrm{~h}$ according to the International standard ISO 4833 . Yeast and fungi were enumerated by using Potatoes Dextrose Agar (PDA) and Escherichia coli and coliform enumeration was performed by Eosin Methylene Blue Agar (EMB). Three replicates were analyzed and expressed as log CFU.g ${ }^{-1}$ fresh weight.

\subsection{Statistical Analysis}

Statistical analysis was performed in SAS 9.0 software. Mean \pm sd was compared by Anova and Duncan's test. The data was used at a significance level of 0.05 . Three replicates were used in experiment.

\section{Results}

\subsection{Effect of SC on the Quality of Fresh-Cut Green Oak Lettuce}

Browning of fresh-cut green oak lettuce salad after treated with SC solutions is shown in Fig.1A. The browning initial presented on day 2 of storage and score of all treatments steady increased during of storage. Fresh-cut green oak salad was immersed with filtered water had highest browning score. At the end of the storage (day 8), browning score was moderate brown of all cut surface of fresh-cut green oak salad (2.30 score). While fresh-cut green oak lettuce was immersed with $50 \mathrm{ppm}$ SC had more effect on inhibit browning than immersing with 100 ppm SC even they were no significant difference.

The weight loss of fresh-cut green oak lettuce during storage at $4^{\circ} \mathrm{C}$ is shown in Fig.1B. Weight loss of all treatments increased little during of storage. Fresh-cut green oak lettuce treated with $100 \mathrm{ppm}$ SC showed significant lower percentage of weight loss than $50 \mathrm{ppm}$ SC treated samples and the control samples. The $50 \mathrm{ppm}$ treated samples had similar percentage of weight loss with the control, and they were no significant different.

Effect of SC on shear force of fresh-cut green oak lettuce is showed in Fig. 1C. There was decreasing of shear force in all treatments. However, $50 \mathrm{ppm}$ SC treatment had higher shear force value than other treatments during storage although there were no significant among of treatments. 

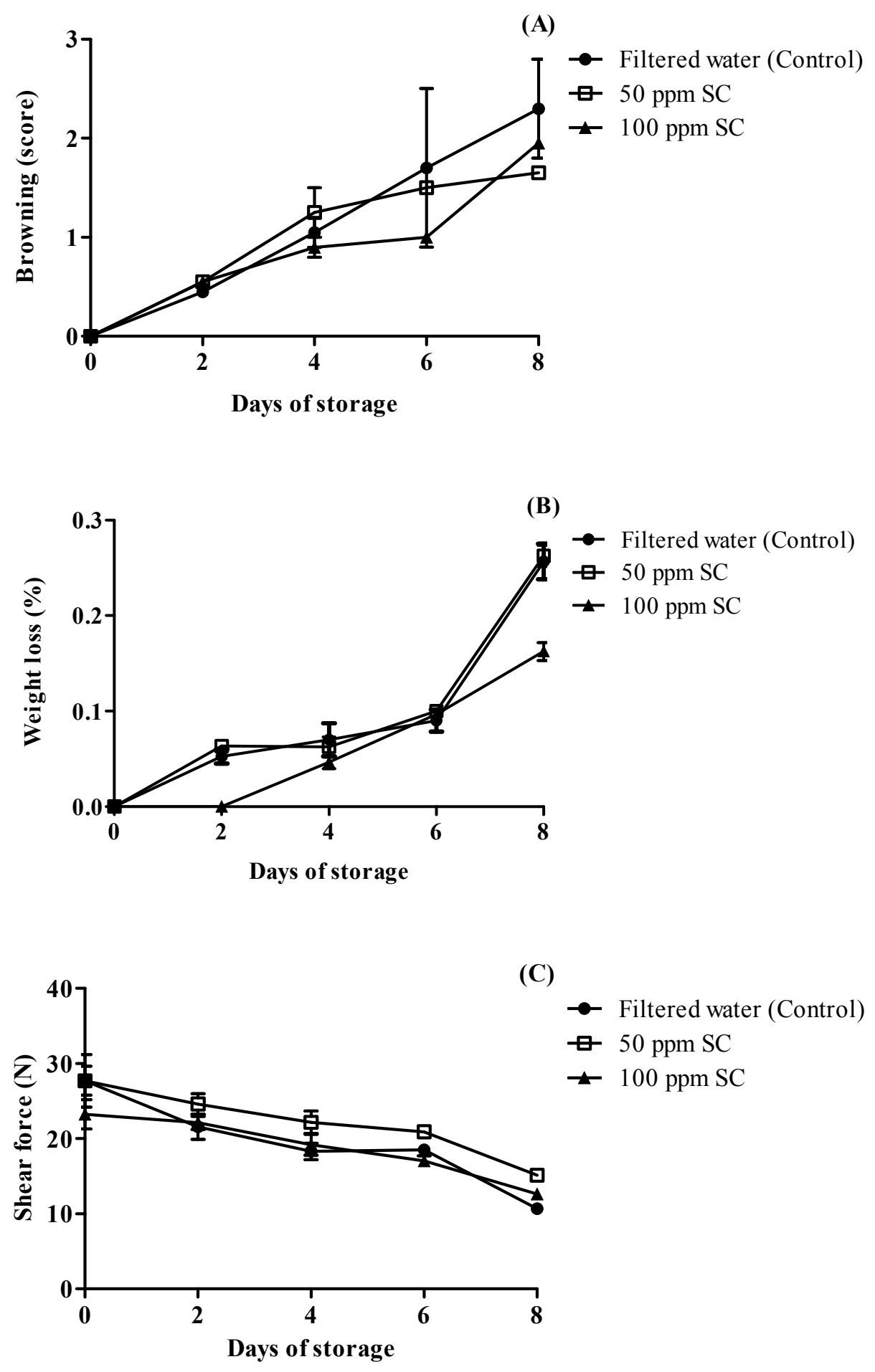

Fig. 1. Browning (A), weight loss (B) and shearing force (C) of fresh-cut green oak lettuces. Fresh-cut green oak lettuces were immersed with filtered water for $5 \mathrm{~min}, 50$ and 100 ppm sodium chlorite (SC) for 1 min before storage at $4^{\circ} \mathrm{C}$ for 8 days.

\subsection{Effect of SC on Microbial Growth}

E. coli and coliform populations on fresh-cut green oak lettuce that immersed with filtered water, 50 and $100 \mathrm{ppm} \mathrm{SC}$ for $1 \mathrm{~min}$ during storage is presented in Fig. 2A. Lettuce immersed with $100 \mathrm{ppm} \mathrm{SC}$ was the best treatment to reduce
E. coli and coliform populations significantly in compared with filtered water treatment. This could be reduced in the range of $5.62-4.79 \log \mathrm{CFU}_{\mathrm{g}}{ }^{-1}$ respectively. However, immersing fresh-cut green oak lettuce with 50 and $100 \mathrm{ppm}$ sodium chlorite for $1 \mathrm{~min}$ did not any effects to inhibit the growth of aerobe bacteria (Fig. 2B). The same result was 
found in yeast and fungi population as shown in Fig. 2C. throughout of storage.

There were no significant differences in all treatments
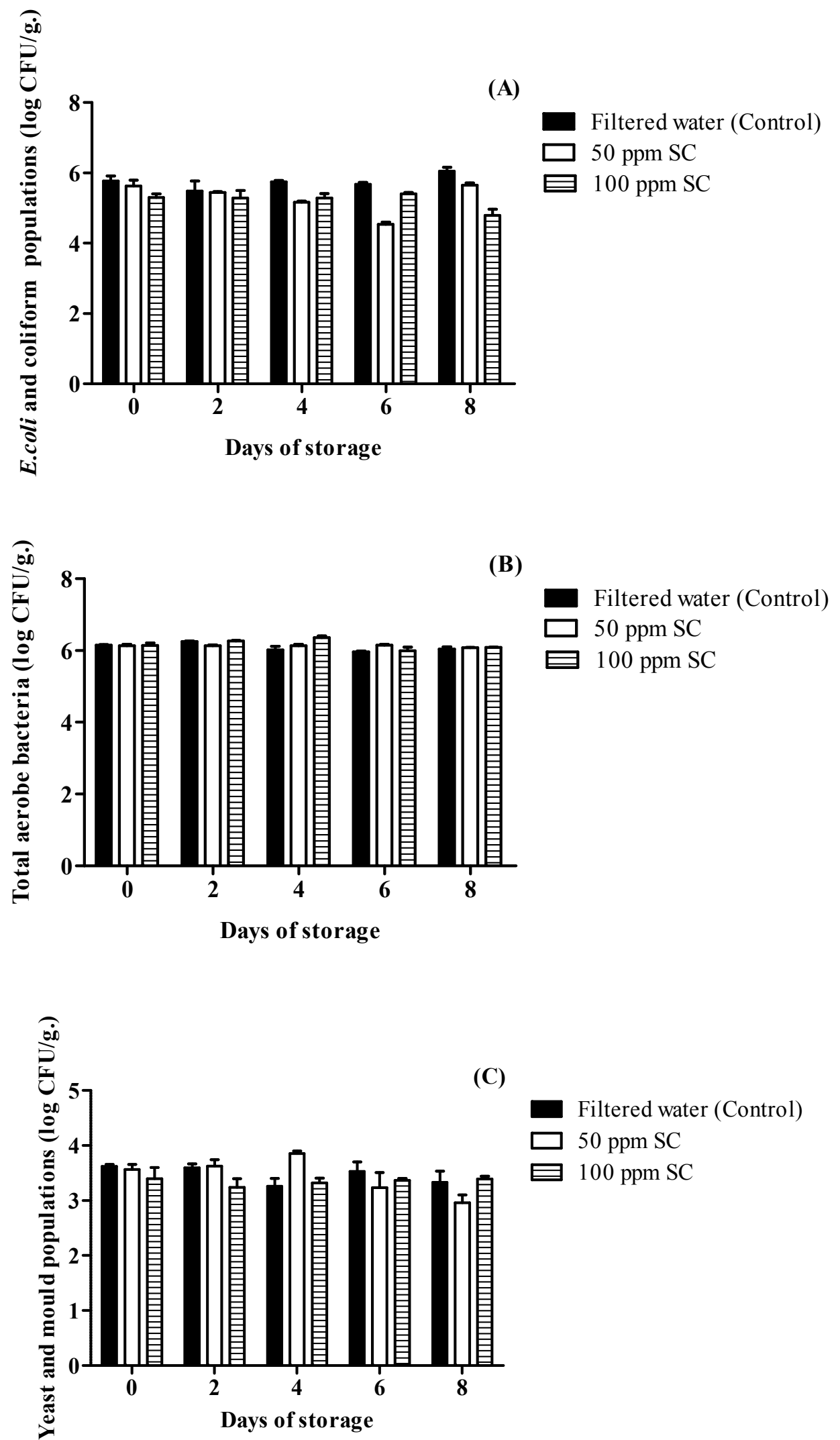

Fig. 2. The population of E.coli and coliform counts (A), total aerobe bacteria (B), and yeast and mould (C) on fresh-cut green oak lettuces. Fresh-cut green oak lettuces were immersed with filtered water for $5 \mathrm{~min}, 50$ and 100 ppm sodium chlorite (SC) for 1 min before storage at $4^{\circ} \mathrm{C}$ for 8 days. 


\section{Discussion}

Cutting, trimming or peeling is major cause of rapid deterioration and short shelf life of fresh-cut produce. Particularly browning is one of the most important problems that occur in fresh-cut fruits and vegetables. When plant tissue is damaged, polyphenol oxidase (PPO) from the cut surface is easy to oxidize with phenolic compounds resulting in browning pigment (Altunkaya \& Gökmen, 2009). Moreover, opened wound on the cut surface is easy to contaminate with many microorganisms. $\mathrm{Lu}$ et al. (2007) demonstrated that $\mathrm{SC}$ has the dual role in browning inhibition and pathogen inactivation. Therefore SC may have the potential to control browning and microbial growth in freshcut produce. In this study, the preventing browning and reducing microbial population in fresh-cut green oak lettuce by sodium chloride (SC) was investigated. Our result showed that SC solution (both at 50 or $100 \mathrm{ppm}$ ) was able to reduce browning on fresh-cut green oak lettuce. Similar result had been reported in fresh-cut zucchini, cucumber, green bell pepper, potato, carrot, and radish by Sun et al. (2012). Since PPO is a copper-containing enzyme in its active site. The copper maintains an equilibrium between enzyme- $\mathrm{Cu}^{2+}$ and enzyme-CU ${ }^{+}$during enzymatic browning (McEvily et al., 1992; Whitaker, 1972). Whereas SC can oxidize $\mathrm{Cu}^{+}$into $\mathrm{CU}^{2+}$ leading to un-equilibrium between enzyme- $\mathrm{Cu}^{2+}$ and enzyme-CU ${ }^{+}$, resulting in alternating of browning reaction. Moreover, SC also oxidizes phenolic compounds which are the precursor of PPO and peroxidase (POD) resulting in delay browning (Lu et al., 2007; He et al., 2008).

Weight loss of fresh-cut green oak lettuce slightly increased throughout storage period in all treatments, particularly, SC treatment at $100 \mathrm{ppm}$ showed the lowest in the weight loss in compared with other treatments. Actually fresh-cut produce are easy to loss water after tissue exposure to the ambient. But there was very little low weight loss of fresh-cut lettuce in this experiment. This is due to fresh-cut lettuce was packed and heat sealed with poly propylene film which help to keep the high moisture inside the package resulting in low transpiration (Manolopoulou \& Varzakas, 2013). Treatments with SC solutions did not have any effect on firmness of fresh-cut lettuce when compared with the control. The shear force values or crispness of SC treated and non treated lettuce decreased with similar levels during storage. Low shear force indicated that plant cells lost turgor pressure leading to deterioration (Martin-Diana et al., 2005).

Efficacy of SC on the inhibition of microbial growth was differences depend on concentrations, contact time, type of fresh-cut produce, $\mathrm{pH}$ of water, and the population of microbial contaminated in fresh-cut produce. Our result found that immersing fresh-cut lettuce in SC solution at 100 ppm had efficiency to reduce E.coli and coliforms counts more than 50 ppm SC solution. Similar result was reported in fresh-cut cilantro. Allende et al. (2009) found that fresh-cut cilantro treated with acidified SC (ASC) at 1 g. $\mathrm{L}^{-1}$ could reduce pathogenic microflora more than 3 log CFU.g ${ }^{-1}$ whereas the lower concentration of ASC $\left(0.25\right.$ and 0.5 g.L $\left.\mathrm{L}^{-1}\right)$ could reduce the microbial population by $2 \log$ CFU.g ${ }^{-1}$. However, SC was as effective as ASC at $1 \mathrm{~g} . \mathrm{L}^{-1}$ in reducing aerobic mesophillic bacteria and E.coli $\mathrm{O} 157: \mathrm{H} 7$ population. Antimicrobial action of SC was hypothesized by Warf et al. (2001). The mode of action of SC derives from the uncharged chlorous acid which is able to penetrate bacterial cell walls and disrupt protein synthesis by virtue of its reaction with sulfhydryl, sulfide, and disulfide containing amino acids and nucleotides. However, the present study showed that SC treatments at 50-100 ppm (0.05-0.1 g. $\left.\mathrm{L}^{-1}\right)$ did not inhibit the growth of total aerobe bacteria and yeasts and molds, Allende et al. (2009) also reported that SC treatment was not effective in reducing yeast and mould population in fresh-cut cilantro.

\section{Conclusions}

Immerssing fresh-cut green oak salad in $100 \mathrm{ppm}$ cooled sodium chlorite for $1 \mathrm{~min}$ and stored at $4{ }^{\circ} \mathrm{C}$ has efficacy on reduction of microorganisms, particularly E. coli and coliform populations. Moreover, sodium chlorite could maintaining fresh weight. However, sodium chlorite could not reduce total aerobic bacteria, yeast and mould populations and maintain firmness. These results may be providing for applications sodium chlorite to improve the quality and safety of fresh-cut produce.

\section{Acknowledgements}

This work was supported by the Thailand Research Fund (TRF, grant No. MSD56I0175) and King Mongkut's University of Technology Thonburi, Bangkok.

\section{References}

[1] Allende, A., Selma, M.V., Lopez-Galvez, F., Villaescusa, R. Gil, M.I. (2008). Role of commercial sanitizers and washing systems on epiphytic microorganisms and sensory quality of fresh-cut escarole and lettuce, Postharvest Biology and Technology, 49, 155-163.

[2] Allende, A., McEvoy, J., Tao, Y., \& Luo, Y. (2009). Antimicrobial effect of acidified sodium chlorite, sodium chlorite, sodium hypochlorite, and citric acid on Escherichia coli $\mathrm{O} 157: \mathrm{H7}$ and natural microflora of fresh-cut cilantro. Food Control, 20, 230-234.

[3] Altunkaya, A,, \& Gökmen, V., (2009). Effect of various antibrowning agents on phenolic compounds profile of fresh lettuce (L. sativa). Food Chemistry, 117, 122-126.

[4] Chen, Z., Zhu, C., Zhang, Y., Niu, D., Du, J., (2010). Effects of aqueous chlorine dioxide treatment on enzymatic browning and shelf-life of fresh-cut asparagus lettuce (Lactuca sativa L.). Postharvest Biology and Technology, 58, 232-238.

[5] Degl'Innocenti, E., Pardossi, A., Tognoni, F., \& Guidi, L. (2007). Physiological basis of sensitivity to enzymatic browning in 'lettuce', 'escarole' and 'rocket salad' when stored as fresh-cut products. Food Chemistry, 104, 209-215. 
[6] Gómez-López, V.M., Ragaert, P., Jeyachchandran. V., Debevere, J., \& Devlieghere, F., (2008). Shelf-life of minimally processed lettuce and cabbage treated with gaseous chlorine dioxide and cysteine. International Journal of Food Microbiology, 121, $74-83$.

[7] He, Q., Luo, Y., \& Chen, P. (2008). Elucidation of the mechanism of enzymatic browning inhibition by sodium chlorite. Food Chemistry, 110, 847-851.

[8] Ibrahim, R., Osman, A., Saari, N., \& Rahman, R.A. (2004). Effects of anti-browning treatments on the storage quality of minimally processed shredded cabbage. Food, Agriculture \& Environment, 2, 54-58.

[9] Keskinen, L. A., Burke, A., \& Annous, B.A. (2009). Efficacy of chlorine, acidic electrolyzed water and aqueous chlorine dioxide solutions to decontaminate Escherichia coli $\mathrm{O} 157: \mathrm{H} 7$ from lettuce leaves. International Journal of Food Microbiology, 132, 134- 140.

[10] Kim, D.H., Kim, H.B., Chung, H.S., \& Moon, K.D. (2014). Browning control of fresh-cut lettuce by phytoncide treatment. Food Chemistry, 159, 188-192.

[11] Lu, S., Luo, Y., Turner, E., \& Feng, H. (2007). Efficacy of sodium chlorite as an inhibitor of enzymatic browning in apple slices. Food Chemistry, 104, 824-829.

[12] Luo, Y., Nou, X., Yang, Y., Alegre, I., Turner, E., Feng, H., Abadias, M., \& Conway, W. (2011). Determination of free chlorine concentrations needed to prevent Escherichia coli O157:H7 cross-contamination during fresh-cut produce wash. Journal of Food Protection, 74, 352-358.
[13] Manolopoulou, E., \& Varzakas, T.H. (2013). Effect of Modified Atmosphere Packaging (MAP) on the Quality of 'Ready-To-Eat' Shredded Cabbage. International Journal of Agricultural and Food Research, 2, 30-43.

[14] Martin-Diana, A.B., Rico, D., Barry-Ryan, C., Frias, J.M., Mulcahy, J., \& Henehan, G.T.M. (2005). Calcium lactate washing treatments for salad-cut Iceberg lettuce: effect of temperature and concentration on quality retention parameters. Food Research International, 38, 729-740.

[15] McEvily, A.J., Iyengar, R. \& Otwell, W.S. (1992). Inhibition of enzymatic browning in foods and beverages, Critical Reviews in Food Science and Nutrition, 32, 253-273.

[16] Sun, S.H., Kim, S.J., Kwak, S.J. \& Yoon, K.S. (2012). Efficacy of sodium hypochlorite and acidified sodium chlorite in preventing browning and microbial growth on fresh-cut produce. Preventive Nutrition and Food Science, 17, 210-216.

[17] Warf, C.C., JR., Kemp, G. K. (2001). The chemistry and mode of action of acidified sodium chlorite. In 2001 IFT Annual Meeting (pp. 1-91). New Orleans.

[18] Whitaker, J.R. (1992). Polyphenol oxidase. In J.R. Whitaker (Ed.), Principles of enzymology for the food sciences (pp. 571-582). New York: Marcel Dekker.

[19] Zagory, D. (1999). Effects of post-processing handling and packaging on microbial populations. Postharvest Biology and Technology, 14, 313-321. 